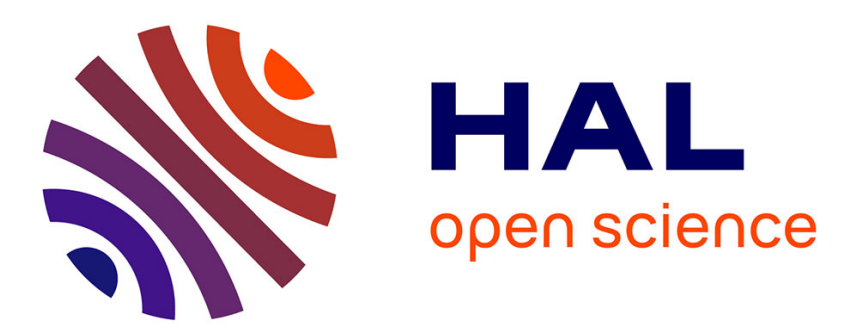

\title{
The Test Bed Island: Tech Business Experimentalism and Exception in Singapore
}

Brice Laurent, Liliana Doganova, Clément Gasull, Fabian Muniesa

\section{To cite this version:}

Brice Laurent, Liliana Doganova, Clément Gasull, Fabian Muniesa. The Test Bed Island: Tech Business Experimentalism and Exception in Singapore. Science as Culture, 2021, pp.1-24. 10.1080/09505431.2021.1888909 . hal-03160826

HAL Id: hal-03160826

https://hal-mines-paristech.archives-ouvertes.fr/hal-03160826

Submitted on 5 Mar 2021

HAL is a multi-disciplinary open access archive for the deposit and dissemination of scientific research documents, whether they are published or not. The documents may come from teaching and research institutions in France or abroad, or from public or private research centers.
L'archive ouverte pluridisciplinaire HAL, est destinée au dépôt et à la diffusion de documents scientifiques de niveau recherche, publiés ou non, émanant des établissements d'enseignement et de recherche français ou étrangers, des laboratoires publics ou privés. 


\title{
The test bed island: tech business experimentalism and exception in Singapore
}

Brice Laurent a, Liliana Doganova a , Clément Gasull ab, Fabian Muniesa a

a Mines ParisTech, PSL University, Centre de Sociologie de l'Innovation, CNRS UMR 9217

b SENSE, Orange Labs

Corresponding author: Brice Laurent, Mines ParisTech, 60 Boulevard Saint-Michel, 75006 Paris, France, brice.laurent@mines-paristech.fr

\begin{abstract}
Islands imaginaries are imaginaries of exception, in the dual sense that islands are seen as places like no others (exceptional territories) as well as sites of exceptions to known orders of things (territories of exceptions). In Singapore, these two modalities of exception play a key role in Smart Nation, a program launched by the government in 2014 which shapes the island as an exceptional place for technology-oriented experiments meant for business development. We call this type of experimental practice tech business experimentalism. We investigate how the Smart Nation innovation program, conceived of as an example of tech business experimentalism, defines Singapore as an exceptional territory and a territory of exceptions. By studying how turning the island into a test bed relies on a politics of exceptionality, we show that current analyses of experiments beyond the scientific laboratory have much to gain by examining two related aspects, namely the business orientation of experiments and the exceptions on which they are built. This approach allows us to discuss the transformation of Singapore's territory, the processes whereby certain inhabitants (and not others) are turned into experimental subjects, and the re-definition of policy action as an ability to carve out material and regulatory exceptions.
\end{abstract}

Keywords: Smart Nation, Singapore, experiment, regulatory sandbox, exception, technology business 


\section{The test bed island: tech business experimentalism and exception in Singapore}

\section{Introduction}

Semakau is a $3.5 \mathrm{~km}^{2}$ island, $7 \mathrm{~km}$ away off the coast of Singapore's main island. Its inhabitants were displaced in the 1980s and the island now serves as a landfill and a testing ground for microgrid technologies (fig. 1). These projects involve private energy companies such as Engie and General Electric, and are supported by the Economic Development Board (EDB) of Singapore. While EDB's executive director for cleantech described the project as 'the largest microgrid research and development platform in Southeast Asia (...) instrumental to Singapore's ambition to achieve a global leadership position in microgrids and serve the regional markets' ${ }^{\prime}$, the private companies involved spoke about the exceptional testing environment they benefited from. Semakau therefore appears as a place like no other, an exceptional territory isolated by geographical frontiers, as well as a territory of exceptions, a place where companies can carry out experimentation activities in special conditions.

The island of Semakau is a place designated by the Singaporean government for experimenting with technological systems for the sake of future global market developments. As a space where global companies are welcome to carry out experiments, Semakau is described as a world-scale exceptional place, which provides a small scale illustration of a logic at play in Singapore at large. The projects conducted on Semakau are part of an initiative called 'Smart Nation', which seeks to harness technological innovation for the sake of economic development. When launching Smart Nation in 2014, Prime Minister Lee Hsien Loong situated the program in the continuity of Singapore's history (PMO, 2014). He saw Smart Nation as the continuation of what his father Lee Kwan Yu had envisioned, which he described as the construction of 'a modern city', which soon would be 'a metropolis'.

Since its independence in 1959, the transformation of Singapore has been linked to technological development, under the guise of innovation policies often framed in reference to international practices and discourses after the 1990s (Pfotenhauer and Jasanoff, 2017; Pfotenhauer, Juhl and Aarden, 2018). These innovation policies, from 'Biopolis' to 'Intelligent Island', have been vehicles for Singapore to constantly re-invent its special position on the global economic map (Pfotenhauer, Juhl and Aarden, 2018; Clancey, 2012; Tan, 2012), by self-describing itself as an economic project, a business center, an innovation hub, a technology culture, and an exceptional terrain for globalization (Koh, 2010; Ong, 2006, 2008; Pow, 2011; Roy and Ong 2011). By providing opportunities for global actors to experiment with technologies in controlled environments such as Semakau, these programs evidence that Singapore is imagined as exceptional, in a dual sense of the term. On the one hand, Singapore is self-described as a place like no other. On the other hand, Singapore is a territory of exceptions such as those which can be observed in Semakau, a site where it is possible to do things that would not be conceivable, or even legally feasible, elsewhere. Singapore may be understood as both an exceptional territory and a territory of exceptions.

By focusing on the case of Singapore, we intend to contribute to a better understanding of the ways in which islands are 'imagined' (see the introduction to this special issue) as territories of exception. How, and for what purposes, is the island imagined as 
exceptional? We argue that a contemporary form of exception in Singapore is to be found in innovation programs that adopt an explicit experimental approach for the sake of market development. We propose to call this type of experimental practice 'tech business experimentalism'. We investigate how the Smart Nation innovation program, conceived of as an example of tech business experimentalism, defines Singapore as an exceptional territory and a territory of exceptions, and what this implies for the island itself and its inhabitants.

Doing so implies that we examine in details the discourse and practice of experiments in Singapore's current innovation policies. Works in Science and Technologies Studies (STS) have developed an analytical repertoire to study experimental practices, in scientific laboratories, and, more recently, in domains related to economics, innovation policy, and social practices. These recent works analyze experiments "not just [as] a distinctive method of scientific inquiry but also [as] a genre, an apparatus, and a particular form of publicity or sociality" (Lezaun et al., 2016), which associates explicit references to 'experiments' and 'tests', public demonstrations addressed to certain audiences, and instrumented practices meant to provide valuable outcomes (Laurent, 2016).

Building on these works, we analyze the experimental dimension of current innovation programs in Singapore. We insist on two dimensions, which, we argue, are important for studying experimental practices beyond the scientific laboratory. First, we connect technical experiments and current practices of business development: we speak of 'tech business experimentalism' to characterize a regime of innovation that explicitly refers to the laboratory and experimental practices in order to accompany entrepreneurial ventures. Second, we explore in details the connection between experiments and exception. By studying a series of experimental projects gathered under the Smart Nation umbrella, we show that experimental practices in Singapore are associated with material and regulatory exceptions being carved out on the island. These explorations provide theoretical resources to make sense of current evolutions in innovation policies.

In the following, we start with a discussion of our analytical approach. We then present our empirical materials, and discuss three aspects of Smart Nation, namely the exceptional testing space it requires, the experimental subjects involved, and the layered regulatory and geographical exceptions that it produces.

\section{Analytical perspectives}

\section{Islands as exceptional territories for knowledge production}

Islands are 'sites of innovative conceptualizations, whether of nature or human enterprise, whether virtual or real' (Baldacchino, 2006, 6). They are described, and in some cases actively performed, as special spaces, and often branded as such in relations to external actors, if not directly by outsiders (Baldacchino, 2012). Thus, '[i]slands are frequently shrouded in discourses and practices of exceptionalism' (Mountz, 2015, 639). Island exceptionalism means that islands are envisioned as different from other places, but also as physical spaces characterized by exceptions to existing natural or social 
orders of things. Imagining islands as exceptional often relies on scientific and technological projects conducted in experimental ways. There are numerous examples of islands being turned into experimental sites, often with wider objectives in mind, including military (Lemov, 2005). More recently, climate change has turned low-lying islands into another kind of laboratory for environmental change (Farbotko, 2010), while islands' geographical particularities have made some of them prone to adopt the discourse and projects of the experimental 'eco-city' (Grydehøj and Kelman, 2016).

These interventions use certain geographical characteristics, such as remoteness or the small size of islands, as resources to transform them into experimental sites supposed to be exceptional, in a way that plays on a dual idea of representativeness and exceptions. Islands are considered as small-scale models, where a reduced number of parameters, including regulatory constraints, makes it easier to conduct experiments. As such, islands can be said to be 'representative' of external realities, while simultaneously being exceptional because they are remote sites where these realities can be rendered legible, and actively designed. In many instances, such representativeness is the consequence of external entities that turned islands into experimental sites, typically colonial powers, or, more recently, global companies. In all cases, the articulation between islands being exceptional sites and representative of wider realities is yet another manifestation of the fact that imagining islands as places of specificities also relies on global connections that extend far beyond the island itself (Krieg, 2018).

Science and Technology Studies (STS) provide analytical resources to understand how islands are turned into laboratories and with what effects. Isolating a social and material space expected to become a laboratory is a well-known problem in STS analyses of scientific practices (Shapin and Schaffer, 1985; Latour, 1988) and practices of testing (Pinch, 1993). STS scholars have then extended the discussion of experiments to situations where economists test, in vitro or in vivo, their theories or models and thereby re-arrange the economy itself (Callon, 2009; Mitchell, 2005), protesters reinvent the forms of political activism (Barry, 1999; Doubleday and Wynne, 2011), experts devise 'technologies of democracy' (Lezaun and Soneryd, 2007; Laurent, 2011), and users of mundane technologies make sustainable development a matter of personal experience (Marres, 2012).

These analyses have connected explicit references to 'experiments' or 'tests' by scientists, economists and policy-makers with their implications for social inclusion/exclusion, political representation, and the common good. Following these words, we explore who experiments, what or whom is experimented with, who is the audience, and for whom experiments matter, in order to scrutinize how experimental practices articulate the production of knowledge and the imagination of desirable social orders (Jasanoff, 2004; Laurent, 2016). We do so by following two connected analytical threads, which both build on recent STS works.

\section{Local technology experiments for global business development}

The case of Singapore illustrates a situation in which public bodies conduct policy programs explicitly formulated in experimental terms, but not for purely scientific purposes. One can identify there a contemporary regime of innovation that also uses the 
vocabulary of experiments, yet in a different guise than scientific practice. This regime is linked to a culture of business orientation populated with technology clusters, venture capitalists, showcases, startup companies, milestones and fiscal incentives that situate in the viability of markets the key to the 'success' of new technologies.

We can comprehend this culture by drawing on recent STS works that have analyzed 'value creation' as a vocabulary of science and technology politics (Muniesa 2017) that requires investigations of the cultural processes (Muniesa et al., 2017) and the instrumented practices shaping it (Doganova and Eyquem-Renault, 2009; Doganova and Muniesa, 2015). Within such a regime of innovation, experiments are conducted to generate knowledge, but also for business purposes and for the sake of value creation. This means that business models and business uses are part of what is being tested. The audiences before whom the experiments are conducted are diverse, and broader than a public of scientists. They comprise potential investors, partners, and clients (see e.g. Rosental, 2013).

We refer to this regime of innovation that uses experiments for the sake of developing technologies for business purposes as tech business experimentalism. Tech business experimentalism is particularly visible in innovation projects related to 'smart cities', where the vocabulary of experiments is omnipresent, and has been analyzed by a growing body of works (Evans et al., 2016; Karvonen, 2018; Laurent and Pontille, 2018). These works show how experiments have become a vehicle for industrial innovation, and a mode of political and economic ordering of the city granting new roles to private actors and turning urban problems into business opportunities (Laurent and Tironi, 2015). In these situations, experiments rework the city as a collection of testing spaces where technological innovation is seen as a source of social control and economic value.

\section{Experiments and the production of spaces of exception}

Tech business experimentalism requires the delimitation of zones (be they 'living laboratories', or 'innovation districts') expected to serve as experimental sites. STS works have analyzed the material conditions in which experimental enclosures are established, especially in situations in which the boundary between the 'laboratory' and the 'field' - or between 'indoors' and 'outdoors' experimentation-is ductile and fragile (Kelly and Lezaun, 2017; Lezaun, 2011; Lezaun and Porter, 2015; Lezaun, Muniesa and Vikkelsø, 2013). This leads us to add a second element to our analysis of experiments, namely the discourse and practice of exception.

Tech business experimentalism adds regulatory delimitations to material ones. Studies of the use of experiments to govern technologies have shown that regulatory exemption, suspension or alteration can allow, with special conditions of scrutiny and monitoring, and within the boundaries of a secure perimeter, for the exploration of new technological potentials (Millo and Lezaun, 2006). These regulatory measures put the principles and practices of democracy to the test (Laurent, 2011, 2017), and can be read as additional illustrations of the ways in which the manipulation of exception reformulates sovereign power (see Agamben, 2005). This requires us to explore the political consequences of the exceptional spaces that tech business experimentalism relies on. This is even more relevant in contexts, such as Singapore, where neoliberal policies are conducted by strategically using exceptions to otherwise authoritarian rules (Ong, 2006; see also Pow, 2017). 
These considerations justify an examination of the manifestations of both exceptionality and exception under which tech business experimentalism can be conducted. We will see that tech business experimentalism, as expressed in Singapore's Smart Nation program, requires imagining and realizing exceptions. The way it does so both builds on the insularity of Singapore, and reconfigures it as an asset for technology-based economic development. As such, tech business experimentalism will appear as a way of performing an island imaginary based on exceptions, with profound consequences for the archipelago and its inhabitants.

\title{
Materials and methods
}

To examine how the island is imagined as exceptional in the context of current innovation policies, we analyze how experiments are designed and conducted in the frame of the Singaporean 'Smart Nation' program. The Smart Nation program is a governmental initiative that was launched in the mid-2010s with the aim of improving Singapore's economic attractiveness. It makes technological development a central component of the island's political and economic identity, and, by drawing on the global discourse of 'smartness', also connects technology with interventions on and implications of human subjects (Hoe, 2016; Ho, 2017; Kong and Woods, 2018). Since 2014, the Smart Nation program has led to a series of initiatives explicitly framed as experimental, in various domains, including healthcare, finance, transportation, housing, energy and government services.

In analyzing Smart Nation, we explore how experimental practices also carry normative perspectives about the desirable social order. In the case of Singapore and the Smart Nation program, this leads us to focus less on the detailed description of each of Smart Nation's projects and more on how these projects produce the exceptionality of the island and its inhabitants. Accordingly, we build on common references used by the actors involved in the Smart Nation program, and we refer to examples that are particularly illustrative of how Singapore is seen as a territory of exceptions fit for tech business experimentalism. In particular, we refer to experimental projects related to tele-health, e-government, self-driving cars, energy, and financial technologies, which involved private companies, public bodies, and research institutions.

We build on empirical materials that we collected during two collective fieldwork missions conducted in 2017 and 2018. Each fieldwork mission lasted two weeks and involved a group of researchers and students; in total, we conducted 92 interviews with people directly or indirectly involved in innovation policy in Singapore, and the Smart Nation program in particular ${ }^{2}$. The empirical material is composed of interviews conducted with academics, officials in Singapore's government bodies and representatives of private companies involved in experimental projects, as well as the documents produced to describe these projects and the Smart Nation program.

\section{An exceptional experimental space}

\author{
'It's a little bonsai'
}


In April 2015, Prime Minister Lee Hsien Loong spoke at a Smart Nation event and described the specificity of Singapore in those terms:

What is different here, is that here you can prototype and test-bed the new ideas, and you can scale. It's compact, it's a little bonsai, you get it to work, you got the essence of the idea right, it is a rapid prototype, and you can develop the same idea elsewhere. If you can make it work in Singapore, you can have the chance to adapt and apply to other contexts. If it doesn't work in Singapore, it's probably worth a rethink. (PMO, 2015, emphasis added)

Singapore, in his understanding, was the ideal experimental site. A successful experiment in Singapore would make the technology being tested worthy of distribution elsewhere. Numerous projects within the Smart Nation program can indeed be described in those experimental terms. For instance, Microsoft experiments with a device aimed to automatically answer people's queries about administrative matters (such as tax returns or elections), for later replications in other parts of the world: the branches of the 'little bonsai' could generate cuttings that could be planted elsewhere. Philips experiments with 'tele-health', that is, the possibility to remotely monitor patients' health. An international public-private consortium experiments with the use of distributed ledger technology, or blockchain, for clearing and settlement of payments and securities. Facilities for experimenting with automated vehicles have been built to support research and development led by universities and private companies, and inform future standards and regulation.

The Smart Nation program explicitly connected the objective of making Singapore a test bed island with the idea of exceptionality. When he officially launched the Smart Nation initiative in November 2014, Prime Minister Lee Hsien Loong described it as the following 'vision':

Looking ahead, we should aim to be an outstanding city in the world. An outstanding place for people to live, work and play in, where the human spirit flourishes. The world is changing fast. We are a leading city today but other leading cities like San Francisco, New York, London, Sydney, Shanghai, they are attracting capital, talent, ideas. They are building outstanding urban environments. They are pulling ahead of the rest of the pack and even of the rest of the countries which they belong to. We have to move ahead with them and stay up there amongst the leading cities of the world. We owe it to our people and we can do this. We have the people, we have the resources and we have the ability to make it happen. (PMO, 2014, emphasis added)

This excerpt sheds light on how Smart Nation articulated the production of experimental knowledge expected to be reproduced and turned into market objects, with the imagined exceptionality of the experimental space. Exceptionality is not only seen as a characteristic of the island inherited from its history and achieved through the successful policies implemented in the past, but also as an objective that has to be actively sought after. It is inscribed into a narrative of rapid change and competition, in which Singapore has to 'move ahead' and 'stay up'. Singapore is expected to stand out in the world, and its exceptional nature is what will make it a global city (Roy and Ong, 2011).

By many respects, Smart Nation takes at yet another level the self-description of Singapore as an island offering an exceptional space of prosperity for business to thrive. 'Attracting MNCs' (multinational corporations) has been a Singaporean motto since the country's independence in 1965 (Mauzy and Milne, 2002). Singapore's Economic Development Board (EDB), the government agency in charge of economic strategy, has 
been playing a fundamental role in driving this policy (Schein, 1996). EDB policies of business attractiveness consist principally in funding schemes and tax incentives. The Research Incentive Scheme for Companies (RISC), for example, offers up to $30 \%$ cofunding support for R\&D projects (EDB, 2017). The Pioneer Certificate Incentive and the Development and Expansion Incentive offer corporate tax exemptions on income derived from activities that contribute to the economic expansion of Singapore (EDB, 2016). The position of Singapore as a tax haven is abundantly discussed by policy analysts and NGOs (McIntyre et al., 2015; Tørsløv, Wier and Zucman, 2018). The reference to the 'haven'-a shelter, but also an inlet, or an anchorage-is evocative of the type of political geographic exceptionalism that we are examining here (Mountz, 2015). In that sense, Singapore might be another instance of 'special economic zone', where constraints are more lax, and which are crucial in current global economic ordering processes (Ong, 2008).

Recent technology development programs connect this economic exceptionalism with experimental practices. The 'Intelligent Island' program, which aimed to harness the economic promises of information technologies (Tan, 2012) was seen as an opportunity to make Singapore a testing ground for smart cities (Mahizhan, 1999). Within Smart Nation, the 'haven' is attractive to business insofar it provides an ideal terrain for both market and technological experimentations. For example, the microgrid experiment on Semakau island with which we opened this paper focuses both on the devices by which the electricity is being produced in a decentralized manner, and on the systems that distribute it within a network of users. Offering hospitable conditions for business anchorage also means turning the country's territory into a test bed.

\section{Wiring up the island}

Smart Nation adds another element to the configuration of Singapore as an exceptional experimental space, namely the production and use of data, qualified as a 'new currency' (Smart Nation, 2018). The Prime Minister's Office (PMO) described Singapore as 'a highly connected and wired up island' (PMO, 2015). The rhetoric of the Smart Nation initiative makes Singapore an urban space of intense information engineering, a space in which signals of all sorts (from energy consumption to transit to communication to social networks) can be subjected to experiments in order to optimize flows, improve service and create value. One can easily identify here the connection with the contemporary discourse of the 'smart city', which makes the production, use and optimization of data an engine for the re-organization of the city (Kitchin, 2014).

Thus, turning Singapore into a Smart Nation requires a work of infrastructural preparation of the test bed island. This preparatory work focuses on cluttering the island with apps and sensors of all sorts that guarantee the availability of data. The island's capacity to produce data was highlighted in a report published by the Infocomm Development Authority of Singapore, which imagined a 'nation-wide sensor network through which data can be captured, shared and analysed' as 'underpinning the Smart Nation' (IDA, 2014). Conducted under the banner of 'open data' and the 'internet of things', this project led to the deployment of video surveillance in public areas, environmental sensors and connectivity infrastructure. This included in particular a collaboration between the Government Technology Authority and the Land Transport Authority to use the country's lamppost infrastructure for the capture and transmission of environmental data such as temperature and humidity, and with other various 
agencies for the use of video surveillance analytics to detect anomalies and traffic patterns (GovTech, 2017).

The idea of a network of sensors that would ultimately cover the entire territory wears the traits of a daunting futurist utopia, reminiscent of both George Orwell's Nineteen Eighty-Four and of Walt Disney's original EPCOT ('Experimental Prototype Community of Tomorrow') project. The embedding of digital technologies within urban infrastructures in Singapore can indeed be studied with these kinds of tensions in mind (Kong and Woods, 2018). In the context of Smart Nation, these developments are part of what is expected to turn Singapore into the 'Living Laboratory' that the Smart Nation initiative envisions (Kong and Woods, 2018; Huiling and Goh, 2017). In order to acquire the defining features of a laboratory, the island needs to be 'wired up' so that the production, monitoring and analysis of data become viable.

Wiring up the island is an opportunity to build the city-state as an exceptional territory by extending tech business experimentalism to infrastructures. As scholars of digital urban innovation have observed, data infrastructures are both platforms for experiments and themselves topics of experiments (Coletta, 2018). In Singapore, the production and use of data and information technologies are opportunities for encouraging the development of startups through dedicated initiatives meant to improve the wiring-up process. By turning data infrastructures into experimental objects, Singapore offers conditions for entrepreneurial ventures to demonstrate the relevance of their technologies to global markets.

Eventually, data visualization technologies are themselves vehicles for further wiring-up the island, and extend the possibilities for testing. The example of Virtual Singapore is illuminating in this respect. Virtual Singapore is a three-dimensional city model and collaborative data platform built by government agencies in collaboration with Dassault Systems, an IT company. It is supposed to serve as a virtual double of the city, on which different types of publics would be able to experiment with potential urban development projects. The platform aggregates different sources of data, either readily available or collected on purpose. One informant told us about a recent project in which 45,000 portable sensors were distributed to students to trace their movements. The sensors recorded data such as the 'level of noise' to which the students were exposed, the 'quality of Wi-Fi coverage', and their self-evaluated 'positive or negative mood', and these data then fed the platform.

This later example shows that if wiring up the island in order to transform it into an exceptional experimental space involves setting up infrastructures, it also requires intervening on people. As they are expected to act in the collection and use of data, or be passively monitored, Singapore's inhabitants are part of the experiments. In the following section, we explore more systematically the role of the population within the Smart Nation initiative.

\section{Experimental subjects}

\section{'Instant Asia'}

The term 'nation' in the Smart Nation program ought to be considered as more than just an amplification of the smart city motto. In Singapore, the population is a resource for 
tech business experimentalism. Consider for instance the experiments conducted by Microsoft and Philips, which we briefly mentioned above: Microsoft experiments with speech recognition algorithms, and Philips experiments with tele-health approaches. Both companies frame their technologies as solutions to global problems, for which Singapore could provide an ideal test bed. Both Microsoft's and Philips' projects involved Singapore's inhabitants, expected to use the technologies being tested. As managers from these two companies explained to us, the characteristics of Singapore's inhabitants made testing in Singapore particularly interesting for them.

That the population is ethnically diverse and speaks several Asian languages (Chinese, Tamil and Malay) makes it an ideal target for artificial intelligence experiments. 'Our intent in working with Singapore is to experiment with technology to learn', the representative of Microsoft told us. He considered that Singapore made it possible to learn about such crucial aspects as 'how do we do with language and nuance'. Singapore could then be a model of larger groups of people, and possibly be representative of the whole of Asia. This echoes other scientific practices in Singapore, particularly related to biotechnology, where the ethnic diversity of the country has been increasingly seen as an asset for global pharmaceutical companies to conduct medical research (Clancey, 2012; Ong, 2006). As Greg Clancey notes:

This concept of the population's racial diversity as a medical research resource invoked a much earlier tourist slogan of Singapore as 'Instant Asia', a place where all major races could be seen and experienced in one spot, close at hand. (Clancey, 2012, 32)

Philips did not use the expression 'Instant Asia', but what its representative told us follows this direction: 'If I can demonstrate to health ministers in Malaysia, Indonesia or the Philippines that it works in Singapore, then they'll buy it'. This characteristic of Singapore was so important for him that he had no troubles stating that the experiments his company conducted in Singapore were not expected to make a profit. Whatever could be earned or lost in Singapore during the experiment would be dwarfed by the future contracts that could be secured elsewhere in Asia, once neighboring countries would be convinced of the value of Philips' health technological solutions. In other words, the commercial gains and losses on the island do not really matter for the experimenters; what matters is the possibility to demonstrate-to prospects located abroad-that the technology works by experimenting on it.

This aspect of tech business experimentalism in Singapore relies on a population that is imagined as exceptional. If this exceptionality is partly linked to its ability to provide a small-scale model of Asia, it is also linked to Singapore's specificities. For once, Singapore is in many respects entirely different from other Asian places. If racial diversity can be used as an asset for biomedical experiments in Singapore, it is also because of Singapore's 'high quality clinical databases' (Clancey, 2012, 32). If Philips' experiment has high demonstrative value, able to convince across Asia, it is because a dense infrastructure makes it possible to track data generated in the pilot, confront them with others, and eventually produce robust demonstrations.

The differences in using Singapore's population as an experimental resource also relate to the imagined characteristics of the island's inhabitants. Consider how the representative of Microsoft described how the test of a chatbot could leave aside complex issues such as privacy:

Singapore is a site with low friction, it's high-tech oriented. There's not so much issue with privacy. In such a project, there are a thousand things to figure out, so if I have privacy 
solved (...) then I can start testing the hard technical things first. (Interview, February 2016)

For him, the issue of privacy was 'solved', because it was simply 'not an issue' for the population. As a scientist would isolate a parameter to test it while others would remain stable, Microsoft experimented with the technical components of its technology while considering that other parameters, potentially sensitive elsewhere because of the social issues they raise, could be left aside. Philips benefited from a similar situation as Singapore's regulatory framework made it possible for the company to operate a health platform in its buildings, and manage it without risking public outcry. Considering that experimenting only the technical part of a system while leaving aside its social aspects supposes that the latter are a context in which the former needs to fit. This understanding of innovation can be questioned. But regardless of the description of innovation processes it proposes, the discourse of the companies experimenting in Singapore says much about the particularities of Singapore as an experimental site. Singapore can become a test bed island because its exceptional population makes it a space of exception.

\section{'Citizen-centric'}

The Philips and Microsoft examples can be seen as outcomes of the explicit strategy of the Singaporean government that consists in attracting MNCs in developing technological programs. They might lead us to think that Singapore is being sold as a laboratory where inhabitants can be guinea pigs for foreign companies to experiment on them (see Holden and Demeritt, 2008). The experimental citizen, however, is more than a passive experimental subject. One of the slides that Philips used to present its project to us claimed that 'in Smart Cities/Nations, citizens are taking ownership of their health'. The representative of Microsoft we met stated that 'within Smart Nation, one of the government's concerns is: how does it impact the common man?'.

This suggests that Singapore's current programs embodying tech business experimentalism imagine a citizen that would benefit from innovation. With the Smart Nation program, the test bed island is indeed qualitatively configured as a living society, as a tech-savvy culture, an exceptional ground from which new ideas would emerge, a generative place in which new technologies, regulations and businesses are tested. As he described Smart Nation, Prime Minister Lee Hsien Loong's stressed the importance of 'a culture':

You can import the latest technology, you can implement business-friendly schemes, but ultimately, you need a culture, (...) daring to dream, daring to fail, daring to take on big challenges. (PMO, 2015)

An indication of what this 'culture' might be was provided to us when we heard the director of Smart Nation at an event at the National University of Singapore in February 2018. He stated that the whole objective of the program was to be 'citizen-centric'. By which he meant that technological innovation would benefit the citizen, and that he or she would take part in it, for instance by participating in the creation of startups or intervening in the collection and use of urban data. The idea of being 'citizen-centric' is not foreign to the global discourse of smart city. In Singapore it suggests examining another way of delineating the space of exception, by determining who is exceptional enough to be part of the transformation of the nation into a 'smart community'. 
This question was explicitly raised during a 2015 public event held at Singapore's Museum of Art and Science, a brand new addition to the city's skyline on Marina Bay. This event was entitled 'The Smart Nation speaks', and was sponsored by the Infocomm Media Development Authority (IMDA). Speakers discussed about who would speak in the name of the smart nation, and for the benefit of whom. One of them questioned whether citizens would have the possibility of 'opting out' from the transformation of Singapore into a Smart Nation. As numerous initiatives within the overall Smart Nation program aim at transforming Singaporeans, turning university students into entrepreneurs or aging citizens into computer code learners, this question resonated with concerns of government bodies.

In its account of the event on its website, the IMDA endorsed the need to shift the narrative of Smart Nation 'from one of exclusion to one of ownership' (IMDA, 2019). This shift directly echoes the idea of Smart Nation being 'citizen-centric'. It re-formulates the concern about opting out into an issue of ensuring a wider and active participation of the population of Singapore. Citizens are therefore expected to take part in tech business experimentalism as any of them is expected to be involved in both technical (e.g. feeding and using data) and business (e.g. launching a startup) experimental activities. This re-formulation also invites us to question the extent of the 'ownership' of the Smart Nation transformation, and the delineation between who is expected to take part in tech business experimentalism and who is not.

This issue was addressed by our informants, as several public officials or representatives of private companies connected the optimization and automation promised by the Smart Nation program with the possibility to act on the structure of the labor force. For instance, an interviewee from the trade association for the tech industry in Singapore described the growing use of information technologies as an engine for the replacement of cheap labor forces. As he put it, 'there was a huge Smart Nation push towards automation' as a solution for industries such as manufacturing, retail, catering or tourism, which relied on low-income jobs. In a similar vein, public officials dealing with the future of land transport in Singapore described self-driving vehicles as crucial for Singapore to deal with a shortage of labor force able to provide drivers.

Within the ongoing global debate about the effect of technological innovation on labor structures, the case of Singapore is particular. About thirty percents of the population of Singapore are 'nonresidents', of which the majority are temporary workers providing a cheap labor force residing outside the island. The migration question has become sensitive in Singapore. The 2011 general election after which the People Action Party (PAP) got its lowest result since the country's independence has been interpreted by political scientists and government officials as a reaction against attempts at setting ambitious targets for migration-fueled demographic growth. Since then, the evolution and control of the migration of transient workers coming from poorer Asian countries have been much debated, even as the discourse promoting the active intervention of the state in attracting 'global talents' is dominant (Krishna and Sha, 2015; Koh, 2010). The problematic situation of migrant workers illustrates that ensuring the exceptionality of Singapore's population also means leaving aside some of its current or would-be inhabitants, if not actively excluding them from the island. Thus, tech business experimentalism is also associated with other kinds of exceptions, - about who can be exceptional and who cannot-and may well result in additional exclusion. 


\section{Layered exceptions}

\section{Experimental zones}

Tech business experimentalism also implies that physical and regulatory spaces of exceptions are delineated within the island of Singapore, as ways of attracting both a global audience of companies and a local audience of would-be innovators and entrepreneurs. There are many examples of districts or islets that are configured within the island of Singapore to serve as experimental zones delineated by physical means. We opened this paper with the artificial island of Semakau, described as the 'first-of-its-kind offshore landfill' 3 , and which has become an experimental site for energy innovation, following agreements between the Economic Development Board (EDB), the Energy Research Institute at Nanyang Technological University, and multinational companies such as Schneider Electric and Engie ${ }^{4}$. The particular target are electricity microgrids, that is, localized groups of energy production technologies that can typically operate on an 'island mode', that is, function autonomously.

Specific zones in Singapore are not necessarily delineated following their physical features like in the case of Semakau island. For example, several zones have been carved out on Singapore's main island order to conduct experiments on self-driving vehicles within the Smart Nation program. Some of them are isolated from the real life of the city, while others are deployed in inhabited districts that are chosen because of their particularities. One of these districts is One-North, a business park that has been developed as a site dedicated to R\&D and business development. Another one is Sentosa, a resort island close to the city center. When they presented to us the series of selfdriving car experiments underway in Singapore, officials at the Land Transport Authority explained that experimental sites were carefully chosen. In One-North, residents would be used to technological innovation and more prone to accept selfdriving vehicles. The leisure business on Sentosa would make the small island an ideal place to test low-speed self-driving shuttles.

Such specific zones, delineated according to their physical features or standing out for the way of living of their inhabitants, offer exceptional conditions for businesses to experiment technological innovations. When we met with a former member of the ministry of transport who had been involved in the design of these experiments, she described them as both a technological shift and a shift in the 'philosophy of governance'. This latter shift was characterized by a 'sandbox approach' consisting in 'delivering special licenses on a case-by-case basis and operating in controlled environments'.

\section{Regulatory sandboxes}

The 'sandbox approach' is more than a mere metaphor. The Smart Nation program included the establishment of a 'regulatory sandbox' for fintech experimentation. The fintech sandbox was launched by the Monetary Authority of Singapore (MAS) in 2016 with the purpose of turning Singapore into a 'Smart Financial Center' (MAS, 2016a; Woo, 2018). The regulatory sandbox was replicated in the energy and health sectors: in 2017, the Energy Market Authority (EMA) of Singapore launched a sandbox to support energy innovations, and in 2018, the Ministry of Health launched a regulatory sandbox for innovative healthcare models, focusing on telemedicine and mobile medicine. 
The notion of the regulatory sandbox tightly couples tech business experimentalism and the production of spaces of exception. The general idea of the sandbox is straightforward. It is usually presented as a means to promote innovation. The argument goes as follows: without withholding a number of regulatory barriers, at least temporally and within a secured perimeter, some small scale experiments with new technologies, methods, products, services and procedures would be prevented from happening.

For the Monetary Authority of Singapore, the sandbox is expected to enable experimentation 'by relaxing specific legal and regulatory requirements prescribed by MAS, which the sandbox entity will otherwise be subject to' (MAS, 2017). The experimentation is contained within the sandbox through the implementation of 'appropriate safeguards to contain the consequences of failure and maintain the overall safety and soundness of the financial system'. The Energy Market Authority used a similar rhetoric of 'safe spaces' of regulatory requirements being 'relaxed' with some 'safeguards', and with the purpose of ensuring that innovators are not 'deterred' from 'testing their ideas' (EMA, 2017a). Operating in the energy, healthcare or finance sector, entrepreneurs are proposed to enter 'sandboxes' where they can innovate, as toddlers would play within a 'safe space'.

While drawing on the idea of being able to manipulate risky entities within an exceptional environment, regulatory sandboxes are also instruments meant to ensure that the ability to experiment positions Singapore on the map of global economic competition. Thus, the fintech regulatory sandbox was conceived as a response to what was described as an unprecedented transformation of financial services worldwide. Fintech was deemed 'disruptive', and, as the Managing Director of the Monetary Authority of Singapore puts it, 'if we do not disrupt ourselves-in a manner we choosesomebody else will-in a manner we will not like' (MAS, 2016b). Accordingly, regulatory sandboxes are expected to attract local and international experimenters and perform demonstrations addressed to diverse audiences, made of local regulators and global investors. For instance, an entrepreneur, who was in the sandbox when we interviewed her, explained to us that the fintech regulatory sandbox allowed her to put technology into the market in conditions that would have been considered 'illegal' otherwise (a license is mandatory to be able to operate on financial markets) and obtain results that could 'convince venture capitalists' that would not have been convinced otherwise (e.g., by a laboratory test, without people actually using the product). Acting as an entrepreneur itself, Singapore also uses the regulatory sandbox to enhance its position in a global competition for innovation, such as fintech (see Woo, 2016), and for spaces deemed hospitable for tech business experimentalism.

The exceptionality of Singapore as an experimental site for technology and business development is here connected to the situated ability to carve out regulatory exceptions. As in comparable instances of 'regulatory experiments' (Millo and Lezaun, 2006), the meaning of the 'safe space' and the reason why this is considered an 'experiment' reside in the limitation in the scope of the release (e.g. maximum number of customers for a fintech app), in its timespan (e.g. maximum number of months) and in the way the evolution of the market is monitored. The object of experiment relates both to the technology that is supposed to be innovative, the business model that would make deployment possible on a broader scale, and the regulation that would create a hospitable environment for the innovation to emerge and develop. To enter the sandbox, an applicant must demonstrate that her innovation does not fit existing regulation and 
deserves a special treatment. Within the sandbox, the regulation that has been shown to be unfriendly is suspended.

The regulatory sandbox could be interpreted in the terms of a sovereign political jurisdiction being unsettled by market forces. Yet the negotiations of the exceptions introduced by the regulatory sandbox suggest a different interpretation. What constitutes an exception and how this exception is operationalized are defined during these negotiations. In interviews, officials from the Energy Market Authority and the Monetary Authority of Singapore stressed the importance of 'case-by-case' approaches and 'ad hoc' discussions between the regulator and the applicant company. The innovators 'have to tell us what they want to do and why their idea does not fit with the rules', explained an interviewee from the Energy Market Authority. A frequent reason for rejecting applications to the sandbox was the conclusion that the innovation did not need a sandbox because it actually did not break the rules. And even when the misfit between the proposed innovation and existing regulation is apparent, it remains to be seen how the exception will be crafted, that is, which precise rules will be suspended and, as one informant put it, 'how sandbox walls will be erected'.

Rather than the retreat of political jurisdiction in the face of the market, the regulatory sandbox can be analyzed as the redefinition of the political as the ability to strategically lift existing legal constraints by negotiating zones of exception (Agamben, 2005; Dean, 2013). This latter point complements our analysis of how Singapore is imagined as exceptional in current innovation programs. Not only does conducting experiments for business purposes require imagining the island as an exceptional site populated with an exceptional population, it also re-defines political sovereignty as the ability to constitute exceptions.

\section{Conclusion}

Singapore is a perfect site for analyzing how islands are imagined as exceptional, and for what purposes. The repertoire of exception in Singapore is situated within a contemporary regime of innovation that we have called tech business experimentalism: one that combines the rhetoric of laboratory research and that of profit facilitation. It defines the island as an exceptional territory for technology experiments meant for business development, and builds on a series of exceptions within this territory. Some of them differentiate Singapore from the rest of Asia, and possibly the rest of the world. Others redefine the population of the island as a special group of people where technological activities could thrive for business purposes. Eventually, these exceptions run inside the island itself. Not everyone in Singapore can or is expected to be exceptional. Experimental practices require that special material and regulatory zones are crafted within the island.

The case of Singapore's Smart Nation program invites us to analyze how experimental innovation policies rely on business development concerns and the discourse and practice of exception. Tech business experimentalism, as we have labeled it, implies that experiments are conducted for the sake of business development. It uses experiments as technological, legal, and economic operations expected to contribute to value creation. As Singapore is imagined as a 'living laboratory', tech business experimentalism relies on exceptions as much as it introduces new ones. 
Our analysis is necessarily about more than its situated geographic location. First, the island city-state is caught in global flows of capital, technologies and people. It can only be imagined in the terms of exceptionality and exception in the context of the links that connect the island to global corporations expected to act as experimenters on the island, international 'talents' expected to contribute to the prosperity of Singapore, foreign countries where the experiments conducted in Singapore can lead to wider market developments, and foreign workers who have so far provided the city-state with a cheap labor force. It is only because Singapore is envisioned as a hub, in a central and privileged position, that the island can be imagined as exceptional.

Second, the use of exception is connected to competition. Offering a hospitable test bed for innovation is at the core of tech business experimentalism. It is often linked, both in official documentation and in interviews with regulators and entrepreneurs, to a sense of urgency and competition. Competition extends to the ability to turn particular places into spaces of exception. For instance, as the government of Singapore implements regulatory sandboxes, it also stresses that this device is a crucial asset in the competition within global business centers trying to introduce their own regulatory sandboxes. Thus, the reference to exception acquires public meaning within a global landscape defined by competition, whether in strict monetary terms, or in those of an imagined race where cities would seek to become leaders in attracting companies, investors and entrepreneurs.

As the references to 'living labs' proliferate, and the 'regulatory sandbox' approach is gaining growing attention in public bodies, it is crucial to further develop the critical analysis of experiments conducted beyond the scientific laboratory. We have done so by exploring how current experimental practices for innovation purposes connect with business concerns and discourses and practices of exception. This has allowed us to identify the consequences of these connections on inclusion and exclusion dynamics. As a self-described test bed for business purposes, the example of Singapore illustrates an island imaginary (see the introduction of the special issue) where the reference to the exceptionality of the island is accompanied by the delineation of exceptions among the human inhabitants and across the material and regulatory landscape. This is also an invitation to analyze tech business experimentalism elsewhere, and examine how exception is mobilized to turn other places into test beds. One can hypothesize that such analyses will provide resources for the critical examination of other islands of both prosperity and exclusion.

\section{Acknowledgments}

The authors thank the members of the research team for their help in collecting and analyzing the data: Madeleine Akrich, Jérôme Denis, Eric Kerr, David Pontille, Margaret Tan, Tatjana Todorovic, and the students of the Mines ParisTech Public Affairs and Innovation teaching program. This research was made possible with the support of Mines ParisTech, and Tembusu College / STS research cluster at the National University of Singapore. We thank Gregory Clancey for his support. We benefited from a RenaultIMD grant (City Experiments project). We thank the editors of the special issue and Science as Culture, and two anonymous reviewers for their valuable feedback.

\section{References}


Agamben, G. (2005) State of Exception (Chicago, IL: University of Chicago Press).

Baldacchino, G. (2006) Islands, island studies, island studies journal, Island Studies Journal, 1(1), pp. 3-18.

Baldacchino, G. (2012) Islands and despots, Commonwealth \& Comparative Politics, 50(1), pp. 103-120.

Barry, A. (1999). Demonstrations: Sites and sights of direct action, Economy and Society, 28(1), pp. 75-94.

Callon M. (2009) Civilizing markets: Carbon trading between in vitro and in vivo experiments, Accounting, Organizations and Society, 34(3), pp. 535-548.

Callon, M., and Muniesa, F. (2007) Economic experiments and the construction of markets, in D. MacKenzie, F. Muniesa and L. Siu (Eds.), Do Economists Make Markets? On the Performativity of Economics, pp. 163-189 (Princeton, NJ: Princeton University Press).

Clancey, G. (2012) Intelligent Island to Biopolis: Smart minds, sick bodies and millennial turns in Singapore, Science, Technology and Society, 17(1), pp. 13-35.

Coletta, C. et al. (2018) Data-driven cities? Digital urbanism and its proxies, Technoscienza, 8(2), pp. 5-18.

Doganova, L. and Eyquem-Renault, M. (2009) What do business models do? Innovation devices in technology entrepreneurship, Research Policy, 38(10), pp. 1559-1570.

Doganova, L. and Muniesa, M. (2015) Capitalization devices: Business models and the renewal of markets, in M. Kornberger, L. Justensen, A.K. Madsen and J. Mouritsen (Eds.) Making things valuable, pp. 109-125 (Oxford: Oxford University Press).

Doubleday, R., and Wynne, B. (2011) Despotism and democracy in the UK: Experiments in reframing relations between the state, science and citizens, in S. Jasanoff (Ed.), Reframing Rights: The constitutional implications of technological change, pp. 239-261 (Cambridge, MA: MIT Press).

EDB (Economic Development Board, Singapore) (2016) Pioneer Certificate Incentive and Development and Expansion Incentive, available at: https://www.edb.gov.sg/content/dam/edb/en/why\%20singapore/In-PCDEI(updated).pdf, last accessed 01 October 2018.

EDB (Economic Development Board, Singapore) (2017) Research Incentive Scheme for Companies, November 30, available at:

https://www.edb.gov.sg/content/dam/edbsite/downloads/brochures/RISC\%20Bro chure.pdf, last accessed 01 October 2018.

EMA (Energy Market Authority, Singapore) (2017a) Launch of Regulatory Sandbox to Encourage Energy Sector Innovations, available at:

https://www.ema.gov.sg/media_release.aspx?news_sid=20171020Wab84AqS9NXY, last accessed 01 October 2018.

Evans, J., Karvonen A. and Raven, R. (Eds.) (2016) The Experimental City (London: Routledge).

Farbotko, C. (2010) Wishful sinking: Disappearing islands, climate refugees and cosmopolitan experimentation, Asia Pacific Viewpoint, 51(1), pp. 47-60. 
GovTech (Government Technology Agency, Singapore) (2017) Smart Nation Sensor Platform, available at:

https://www.tech.gov.sg/files/media/speeches/2017/05/Factsheet\%20Smart\%20N ation\%20Sensor\%20Platform.pdf, last accessed 9 April 2019.

Grydehøj, A., \& Kelman, I. (2016) Island smart eco-cities: Innovation, secessionary enclaves, and the selling of sustainability, Urban Island Studies, 2, pp. 1-24.

Ho, E. (2017) Smart subjects for a Smart Nation? Governing (smart)mentalities in Singapore, Urban Studies, 54(13), pp. 3101-3118.

Hoe, S. L. (2016) Defining a smart nation: The case of Singapore, Journal of Information, Communication and Ethics in Society, 14(4), pp. 323-333.

Holden, K. and Demeritt, D. (2008) Democratising science? The politics of promoting biomedicine in Singapore's developmental state, Environment and Planning D: Society and Space, 26(1), pp. 68-86.

Huiling, E. and Goh, B. (2017) AI, robotics and mobility as a service: The case of Singapore, Field Actions Science Reports. The Journal of Field Actions, 17, pp. 26-29.

IDA (Infocomm Development Authority, Singapore) (2014) Shaping a Smart Nation: Annual Report 2013/2014, available at https://www.tech.gov.sg/files/media/corporate-publications/2018/01/annualreport-fy-2013-2014.pdf, last accessed 9 April 2019.

IMDA (Infocomm Media Development Authority, Singapore) (2019) Tales of the Smart Nation, available at https://www.imda.gov.sg/infocomm-and-media-news/whatstrending/2015/10/tales-of-the-smart-nation, last accessed 9 April 2019.

Karvonen, A. (2018) The city of permanent experiments?, in B. Turnheim, , P. Kivimaa, and F. Burkhout (Eds.) Innovating Climate Governance: Moving Beyond Experiments, pp. 201-215 (Cambridge: Cambridge University Press).

Karvonen, A. and Heur, B. (2014) Urban laboratories: Experiments in reworking cities, International Journal of Urban and Regional Research, 38(2), pp. 379-392.

Kelly, A. and Lezaun, J. (2017) The wild indoors: Room-spaces of scientific inquiry, Cultural Anthropology, 32(3), pp. 367-398.

Kitchin, R. (2014) The real-time city? Big data and smart urbanism, GeoJournal, 79(1), pp. 1-14.

Koh, A. (2010) Tactical Globalization: Learning from the Singapore Experiment (Bern: Peter Lang).

Kong, L. and Woods, O. (2018) The ideological alignment of smart urbanism in Singapore: Critical reflections on a political paradox, Urban Studies, 55(4), pp. 679701.

Krieg, L. J. (2018). Entangling (non) human isolation and connectivity: Island nature conservation on Ile aux Aigrettes, Mauritius, Island Studies Journal, 13(2), pp. 55-70.

Krishna, V.V. and Sha, S.P. (2015) Building science community by attracting global talents: The case of Singapore Biopolis, Science, Technology and Society, 20(3), pp. 289-413. 
Latour, B. (1988) The Pasteurization of France (Cambridge, MA: Harvard University Press).

Laurent, B. (2011) Technologies of democracy: Experiments and demonstrations, Science and Engineering Ethics, 17(4), pp. 649-666.

Laurent, B. (2016) Political experiments that matter: Ordering democracy from experimental sites. Social Studies of Science, 46(5), pp. 773-794.

Laurent, B. (2017) Democratic Experiments: Problematizing Nanotechnology and Democracy in Europe and the United States (Cambridge, MA: The MIT Press).

Laurent, B. and Pontille, D. (2018) Toward a study of city experiments, in C. Coletta, L. Evans, L. Heaphy and R. Kitchin (Eds.) Creating Smart Cities, pp. 90-103 (London: Routledge).

Laurent, B. and Tironi, M. (2015) A field test and its displacements. Accounting for an experimental model of industrial innovation. CoDesign, 11(3-4), pp. 208-221.

Lemov, R. (2005) World as Laboratory: Experiments with Mice, Mazes, and Men (New York: Hill and Wang).

Lezaun, J. (2011) Bees, beekeepers, and bureaucrats: Parasitism and the politics of transgenic life, Environment and Planning D: Society and Space, 29(4), pp. 738-756.

Lezaun, J. and Porter, N. (2015) Containment and competition: Transgenic animals in the one health agenda, Social Science and Medicine, 129, pp. 96-105.

Lezaun, J., and Soneryd, L. (2007) Consulting citizens: Technologies of elicitation and the mobility of publics, Public Understanding of Science, 16(3), 279-297.

Lezaun, J., Muniesa, M. and Vikkelsø, S. (2013) Provocative containment and the drift of social-scientific realism, Journal of Cultural Economy, 6(3), pp. 278-293.

Lezaun, J., Marres, N. and Tironi, M. (2016) Experiments in participation, in U. Felt et al. (Eds.) The Handbook of Science and Technology Studies, pp. 295-221 (Cambridge: MIT Press).

Mahizhnan, A. (1999) Smart Cities: the Singapore case, Cities, 16(1), pp. 13-18.

Marres, N. 2012. Material Participation: Technology, the Environment and Everyday

Publics (New York, NY: Palgrave Macmillan).

MAS (Monetary Authority of Singapore) (2016a), Smart Financial Center, available at: http://www.mas.gov.sg/Singapore-Financial-Centre/Smart-Financial-Centre.aspx , last accessed 01 October 2018.

MAS (Monetary Authority of Singapore) (2016b), Singapore's FinTech Journey - Where We Are, What Is Next - Speech by Mr Ravi Menon, Managing Director, Monetary Authority of Singapore, at Singapore FinTech Festival - FinTech Conference on 16 November 2016, available at: http://www.mas.gov.sg/News-andPublications/Speeches-and-Monetary-Policy-Statements/Speeches/2016/SingaporeFinTech-Journey.aspx, last accessed 01 October 2018.

MAS (Monetary Authority of Singapore) (2017), FinTech Regulatory Sandbox, available at: http://www.mas.gov.sg/Singapore-Financial-Centre/Smart-FinancialCentre/FinTech-Regulatory-Sandbox.aspx, last accessed 01 October 2018. 
Mauzy, D. and Milne, R. (2002) Singapore Politics under the People's Action Party (London: Routledge).

McIntyre, R., Phillips, R. and Baxandall, P. (2015) Offshore shell games: the use of offshore tax havens by Fortune 500 companies. Citizens for Tax Justice and U.S. PIRG Education Fund.

Millo, Y. and Lezaun, J. (2006) Regulatory experiments: Genetically modified crops and financial derivatives on trial, Science and Public Policy, 33(3), pp. 179-190.

Mitchell, T. (2005) The work of economics: How a discipline makes its world, European Journal of Sociology, 46(2), pp. 297-320.

Mountz, A. (2015) Political geography II: Islands and archipelagos. Progress in Human Geography, 39(5), pp. 636-646.

Muniesa, F. (2017) On the political vernaculars of value creation, Science as Culture, 26(4), pp. 445-454.

Muniesa, F., Doganova, L., Ortiz, H., Pina-Stranger, A., Paterson, F., Bourgoin, A., Ehrenstein, V., Juven, P.-A., Pontille, D., Sarac-Lesavre, B., and Yon, G. (2017) Capitalization: A Cultural Guide (Paris: Presses des Mines).

Ong, A. (2006) Neoliberalism as Exception: Mutations in Citizenship and Sovereignty (Durham, NC: Duke University Press).

Ong, A. (2008) Scales of exception: Experiments with knowledge and sheer life in tropical Southeast Asia, Singapore Journal of Tropical Geography, 29(2), pp. 117-129.

Pfotenhauer, S. M., Juhl, J., and Aarden, E. (2019) Challenging the 'deficit model' of innovation: Framing policy issues under the innovation imperative, Research Policy, 48(4), pp. 895-904.

Pfotenhauer, S., and Jasanoff, S. (2017) Panacea or diagnosis? Imaginaries of innovation and the 'MIT model' in three political cultures, Social studies of science, 47(6), pp. 783810.

Pinch, T. (1993) 'Testing - One, two, three ... testing': Toward a sociology of testing, Science, Technology, \& Human Values, 18(1), pp. 25-41.

PMO (Prime Minister Office, Singapore) (2014) Transcript of Speech by Prime Minister Lee Hsien Loong at Smart Nation launch, 24 November 2014, available at: https://www.pmo.gov.sg/newsroom/transcript-prime-minister-lee-hsien-loongsspeech-smart-nation-launch-24-november, last accessed 9 April 2019.

PMO (Prime Minister Office, Singapore) (2015) Transcript of Speech by Prime Minister Lee Hsien Loong at Founders Forum Smart Nation Singapore Reception on 20 April 2015, available at: https://www.pmo.gov.sg/newsroom/transcript-speech-primeminister-lee-hsien-loong-founders-forum-smart-nation-singapore, last accessed 01 October 2018.

Pow, C.P. (2017) Elite informality, spaces of exception and the super-rich in Singapore, in R. Forrest, S.Y. Koh and B. Wissink (Eds.) Cities and the Super-Rich, pp. 209-228 (New York: Palgrave Macmillan).

Pow, C.P. (2011) Living it up: Super-rich enclave and transnational elite urbanism in Singapore, Geoforum, 42(3), pp. 382-393. 
Rosental, C. (2013) Toward a sociology of public demonstrations, Sociological Theory, 31(4), pp. 343-365.

Roy, A. and Ong, A. (Eds.) (2011) Wordling Cities: Asian Experiments and the Art of Being Global (London: John Wiley).

Schein, E.H. (1996) Strategic Pragmatism: The Culture of Singapore's Economic Development Board (Cambridge, MA: The MIT Press).

Shapin, S. and Schaffer, S. (1985) Leviathan and the Air-Pump (Princeton, NJ: Princeton University Press).

Smart Nation (2018), Open Data Resources, available at: https://www.smartnation.sg/resources/open-data-resources, last accessed 14 October 2019.

Tan, M. (2012) Promises and threats: iN2015 Masterplan to pervasive computing in Singapore, Science, Technology and Society, 17(1), pp. 37-56.

Tørsløv, T., Wier, L. and Zucman, G. (2018) The missing profits of nations. Working Paper 24701. National Bureau of Economic Research.

Woo, J.J. (2016), Singapore as an International Financial Centre: History, Policy and Politics (London: Palgrave Macmillan).

Woo, J.J. (2018), Technology and Governance in Singapore's Smart Nation Initiative, Working Paper, Ash Center for Democratic Governance and Innovation, Harvard Kennedy School, available at:

https://ash.harvard.edu/files/ash/files/282181_hvd_ash_paper_jj_woo.pdf, last accessed 01 October 2018

\footnotetext{
1 'Harnessing energy from the sun, wind and tides on offshore Semakau Landfill' (Audrey Tan), The Straits Times, October 25, 2016; available at:

https://www.straitstimes.com/singapore/harnessing-energy-from-the-sun-wind-andtides-on-offshore-semakau-landfill, last accessed March 9, 2019.

${ }^{2}$ See the Acknowledgement section

3 'World's first offshore landfill constructed from the seabed up is located in Singapore', TheCivilEngineer.org, March 1, 2018, available at:

https://www.thecivilengineer.org/news-center/latest-news/item/1566-world-s-firstoffshore-landfill-constructed-from-the-seabed-up-is-located-in-singapore, last accessed April 9, 2019.

4 This project was described to us during interviews conducted with representatives of Engie and the EDB.
} 